\title{
Synthesis of Silver Nanoparticles Using Dichloromethane-Methanol Flower Extract of Chrysanthemum cinerariaefolium and Its Antibacterial Activity
}

\author{
Caroline Jepchirchir Kosgei ${ }^{1,}$, Festus Tolo ${ }^{2}$, Josphat Clement Matasyoh ${ }^{3}$, Meshack Obonyo ${ }^{1}$, \\ Peter Mwitari $^{2}$, Lucia Keter ${ }^{2}$, James Jorum Owuor ${ }^{4}$, Moses Ollengo ${ }^{5}$, Beatrice Irungu ${ }^{2}$ \\ ${ }^{1}$ Department of Biochemistry, Faculty of Science, Egerton University, Nakuru, Kenya \\ ${ }^{2}$ Centre for Traditional Medicine and Drugs Research (CTMDR), Kenya Medical Research Institute, Nairobi, Kenya \\ ${ }^{3}$ Department of Chemistry, Faculty of Science, Egerton University, Egerton, Kenya \\ ${ }^{4}$ Department of Chemical Science and Technology, School of Chemistry and Material Science, Faculty of Applied and Sciences and \\ Technology, Technical University of Kenya, Nairobi, Kenya \\ ${ }^{5}$ Department of Chemistry, School of Science, Dedan Kimathi University of Technology, Nyeri, Kenya
}

Email address:

rocachep@gmail.com (C. J. Kosgei),fmtolo1@gmail.com (F. Tolo), josphat2001@yahoo.com (J. C. Matasyoh), obonyom@gmail.com (M. Obonyo),pmwitari67@gmail.com (P. Mwitari), lketer3@gmail.com (L. Keter), jjamesowuor@gmail.com (J. J. Owuor), mosesollengo@gmail.com (M. Ollengo), birungu18@gmail.com, (B. Irungu)

${ }^{*}$ Corresponding author

\section{To cite this article:}

Caroline Jepchirchir Kosgei, Festus Tolo, Josphat Clement Matasyoh, Meshack Obonyo, Peter Mwitari, Lucia Keter, James Jorum Owuor, Moses Ollengo, Beatrice Irungu. Synthesis of Silver Nanoparticles Using Dichloromethane-Methanol Flower Extract of Chrysanthemum cinerariaefolium and Its Antibacterial Activity. American Journal of Nano Research and Applications. Vol. 9, No. 1, 2021, pp. 1-8. doi: 10.11648/j.nano.20210901.11

Received: June 16, 2020; Accepted: August 24, 2020; Published: February 23, 2021

\begin{abstract}
Nanotechnology is an emerging field that has opened new horizons in nanomedicine. The use of silver nanoparticles is attracting much interest because of their antibacterial activity. This study involved synthesis of silver nanoparticles using Chrysanthemum cinerariaefolium flowers dichloromethane-methanol crude extract. The synthesized silver nanoparticles (Ag NPs) were characterized using UV-Vis spectroscopy, SEM, EDX, TEM and FTIR. The antibacterial potential of the nanoparticles was ascertained against methicillin-resistant Staphylococcus aureus (MRSA), Pseudomonas aeruginosa, Staphylococcus aureus and Shigella sonnei. This was followed by phytochemical analyses of the crude extracts. The Ag NPs were generally spherical as observed in the SEM and TEM micrographs with an average size of $26.98 \mathrm{~nm}$. The UV- absorption spectrum revealed prominent peak at $430 \mathrm{~nm}$ while EDX analysis showed the percentage abundance of silver nanoparticle at $(81.33 \%)$. The FTIR spectroscopy confirmed absorption bands of various functional groups on the surface of Ag NPs. The absorption bands were at $3472.88 \mathrm{~cm}^{-1}, 3190.67 \mathrm{~cm}^{-1}, 1646.61 \mathrm{~cm}^{-1}, 1405.08 \mathrm{~cm}^{-1}, 1109.32 \mathrm{~cm}^{-1}$ and $518.64 \mathrm{~cm}^{-1}$. Antibacterial potential of the synthesized Ag NPs showed that they were more active on S. aureus with an MIC of 31.25 $\mu \mathrm{g} / \mathrm{ml}$. The phytochemicals observed in the crude extracts that could have been responsible for reducing silver ions into silver nanoparticles were flavonoids, phenols, tannins and glycosides.
\end{abstract}

Keywords: Nanoparticles, Nanotechnology Antibacterial, Phytochemicals

\section{Introduction}

Infectious diseases including bacterial, viral and fungal are among the leading cause of death world-wide [1]. Antibiotics has been the mainstay in the fight against bacterial infections, however this breakthrough has been compromised over the past few decades due to emergence 
of drug-resistant bacteria [2]. This therefore has necessitated a search for novel drugs that target these resistant micro-organisms. Since time immemorial, silver has been known for its anti-bacterial effects and for centuries it has find use in prevention and control of wideranging infections [3]. Advances in nanotechnology have immensely improved the antimicrobial potential of silver and opened new horizons in nanomedicine.

Due to their small sizes, the nanoparticles possess novel physiochemical and biological properties, such as enhanced reactive area and the ability to cross cell and tissue barriers [4].

The most commonly used method for synthesizing nanoparticles is chemical method. This method however may lead to the presence of some toxic chemicals that were used in the reduction of the metal ion to nano size and stabilization of the nanoparticle [5]. As a substitute to chemical synthesis, scientists have devised alternative ways of synthesizing nanoparticles from metal ions using natural products through green synthesis [6]. Green synthesis of nanoparticles has been considered cost-effective, economic, eco-friendly, occur at ambient conditions and uses less chemicals, thus reducing the pollution caused to the environment [6].

Natural products such as plant extracts, fungal extracts and bacterial extracts are rich sources of unmatched chemical entities that can be used to treat various illnesses, besides playing other important roles such as synthesis of nanoparticles [7]. Among the chemical entities present in these extracts are flavanoids, alkaloids, terpenoids, steroids, tannins and phenols. In nanotechnology these chemical entities can act as reducing and capping/stabilizing agents in the reduction of metal ions to metal nanoparticles [8]. The nanoparticles obtained from metal ions can be used in drug delivery [9], tissue/tumor imaging [10], biosensing [11], catalysis [12] and surface-enhanced raman scatteringbased sensors [13].

Plant extracts have been used widely in green synthesis of nanoparticles because they are more stable and the rate of synthesis is faster in comparison to microorganisms [6]. Earlier studies have shown that crude extracts from various plants such as Malachra capitata, alfalfa sprouts, Aloe spp, banana peel, Annona squamosa peel extract, bamboo charcoal, Curcuma longa tuber, Eucalyptus hybrida, Cinnamon zeylanicum bark, Geranium spp, and Capsicum annuum among many other medicinal plants, have been explored for the synthesis of silver nanoparticles $[14,15]$.

The potential of plants to be used in synthesizing nanoparticles, is yet to be fully explored. Therefore, there is still a need to explore other plants whose nano synthesis have not been ascertained. In the present study, silver nanoparticles were synthesized using dichloromethanemethanol crude extract (1: $1 \mathrm{v} / \mathrm{v})$ of Chrysanthemum cinerariaefolium and its antibacterial potential determine against selected bacteria. An analysis of the phytochemical composition of the crude extracts was also carried out.

\section{Materials and Methods}

\subsection{Preparation of $C$. cinerariaefolium Dichloromethane-Methanol Crude Extract}

Pyrethrum flowers were collected from local farmers in Elgeyo-Marakwet County, latitude $0010^{\prime}$ to $0052^{\prime \prime} \mathrm{N}$, Longitude $35025^{\prime \prime}$ to $35045^{\prime \prime} \mathrm{E}$ and altitude of $8389 \mathrm{~m}$ above sea level. Twenty grams of powdered flower material were extracted in $100 \mathrm{ml}$ mixture of methanol and dichloromethane $(1: 1 \mathrm{v} / \mathrm{v})$ at room temperature and evaporated to dryness under reduced pressure. The dichloromethane-methanol crude extract was then used for the green synthesis of silver nanoparticles.

\subsection{Preparation of Silver Nanoparticles}

Synthesis of silver nanoparticles was done according to [16]. Dichloromethane-methanol extract (0.05\%) was prepared by dissolving the crude extract $(12.5 \mathrm{mg})$ in a minimum volume of DMSO $(1 \mathrm{~mL})$, into which distilled water $(24 \mathrm{~mL})$ was added. $1 \mathrm{mM}$ silver nitrate solution $(25$ $\mathrm{mL}$ ) was mixed with same volume of $0.05 \%$ extract and the resulted mixture was incubated at $30^{\circ} \mathrm{C}$ in dark on a linear shaker. Synthesis of silver particles was monitored by using UV-visible spectrophotometer (Agilent technologies cary 60 uv-vis) at $0,3,12,24$ and 48 hrs. Observing a color change of the extracts from light yellow to dark brown also indicated formation of nanoprecipitate. Thereafter, the nanopreparation was centrifuged at $5000 \mathrm{rpm}$ for 10 minutes. The supernatant was discarded and the pellet containing silver nanoparticles was air dried in the incubator.

\subsection{Characterization of Silver Nanoparticles}

\subsubsection{UV-visible Spectroscopy}

The diluted samples were scanned in a UV-vis spectrophotometer (Agilent technologies cary 60 uv-vis) between $300 \mathrm{~nm}$ and $700 \mathrm{~nm}$. The UV-visible spectra of the plant leaf extract and silver nitrate solution were also recorded.

\subsubsection{Scanning Electron Microscopic Analysis}

The surface characteristics of the synthesized silver nanoparticles were determined using scanning electron microscope (SEM Carl Zeiss Ultra Plus). The sample was first converted to a dry powder then gold coated using a sputter coater and mounted on a sample handler. It was then followed by scanning the sample using a focused beam of electrons. The details pertaining applied voltage, magnification used and size of the contents of the images were implanted on the images itself. The elemental analysis of the nanoparticles was carried out by energy dispersive Xray analysis using (EDS) analyzer (Oxford X max) attached on the scanning electron microscope.

\subsubsection{Transmission Electron Microscopic Analyses}

Transmission electron microscope (TEM JEOL, JEM 1010) operating at both normal and high resolution modes (HR TEM) was used to visualize the morphology of the Ag NPs. The silver nanoparticles were first dissolved in 
methanol and a sample of $5 \mu \mathrm{l}$ was placed onto the carbon coated copper grid and a thin film of the sample was made on the grid and drying under lamp.

\subsubsection{Fourier-transform Infrared Spectroscopy (FTIR)}

FTIR analysis of dried Ag NPs was carried out through the potassium bromide (KBr) pellet (FTIR grade) in 1: 100 ratio. The samples were scanned using infrared in the range of 4000-400 $\mathrm{cm}^{-1}$ using Fourier Transform Infrared Spectrometer (FTIR-600 FTIR SPECTROMETER). The spectral data obtained were compared with the reference chart to identify the functional groups present in the sample.

\subsection{Phytochemical Analyses of Dichloromethane-Methanol Crude Extract}

Phytochemical analyses of the dichloromethane-methanol extract was done qualitatively, using standard procedures according to [17]. The tested phytochemicals were tannins, phlobatanins, saponins, flavonoids, steroids, alkaloids, phenols, tannins, glycoside and terpenoids.

\subsection{Antibacterial Assay}

\subsubsection{Test Micro-organisms}

Four bacterial strains $S$. aureus (ATCC 25923), $P$. aeruginosa (ATCC 27853), S. sonnei (ATCC 25931) and MRSA (Clinical isolate) were used for assay of antibacterial activities. The four were obtained from Kenya Medical Research Institute (KEMRI).

\subsubsection{Disc Diffusion Assay}

Antibacterial activity of synthesized Ag NPs were ascertained using disk diffusion method according to [18]. Suspension of selected micro-organisms was subcultured on Mueller-Hinton agar with each strain being swabbed evenly onto individual agar using sterile cotton swabs. Sterile paper disks $6 \mathrm{~mm}$ in diameter impreginated with $500 \mu \mathrm{g} / \mathrm{ml}$ of AgNPs, $0.05 \%$ dichloromethane-methanol extract (control), $\mathrm{AgNO}_{3}$ solution (1Mm) (control), chloramphenicol (positive control) and 1\% DMSO (negative control) were used. The experiment was replicated 3 times. Zones of inhibition were measured in millimeter after $24 \mathrm{hrs}$ of growth and its mean \pm SD determined. Determination of Minimum Inhibitory concentration (MIC) was also done on the extract that caused inhibition above $10 \mathrm{~mm} \pm \mathrm{SD}$.

\subsubsection{Determination of Minimum Inhibitory Concentration (MIC)}

The MIC was determined using the microdilution method as described by [19]. Serial two-fold dilutions of Ag NPs against $S$. aureus was prepared in a 96-well microtiter plate, obtaining a concentration range from 500 $\mu \mathrm{g} / \mathrm{ml}$ to $15.625 \mu \mathrm{g} / \mathrm{ml}$. It was followed by addition of $5 \mu \mathrm{l}$ of $S$. aureus suspension which were added to the wells containing the dilutions. Each dose was assayed in triplicate. Uninoculated wells containing sterile saline and Ag NPs were used as controls. After incubation for $24 \mathrm{hrs}$ at $37^{\circ} \mathrm{C}$, the samples were observed. MIC was recorded as the lowest concentration of Ag NPs that inhibited the bacterial growth minimumly as detected by reduction in turbidity.

\section{Results and Discussion}

\subsection{Colour Change and UV-vis Spectra}

On addition of light yellow dichloromethane-methanol flower extract to colorless silver nitrate solution (figure 1) and storing the solution in the dark for 48 hours, formation of Ag NPs was observed as signified by a colour change of the extract to dark brown colour (figure 2). Observation of colour change as a primary notable evidence of synthesis of silver nanoparticles has been reported in previous studies [20]. The color change observed was due to the excitation of surface plasmon resonance (SPR) by Ag NPs which was then detected in a UV-visible spectrum as a localized peak at $430 \mathrm{~nm}$ (figure 3). This is because Ag NPs have free electrons which give rise to SPR absorption band due to the combined vibration of electrons of metal nanoparticles in resonance with the light wave [21]. As observed in the current study, earlier studies too have confirmed that SPR peak for silver nanoparticle is located within $410-460 \mathrm{~nm}$ regions [22]. The broadening of the curve in the UV-vis spectrum indicated that the nanoparticles were polydispersed [23]. No prominent peak was observed at 410-460 $\mathrm{nm}$ regions in the UV-vis spectrum of silver nitrate (figure 4) and plant extracts (figure 5) an indication of absence of SPR band.

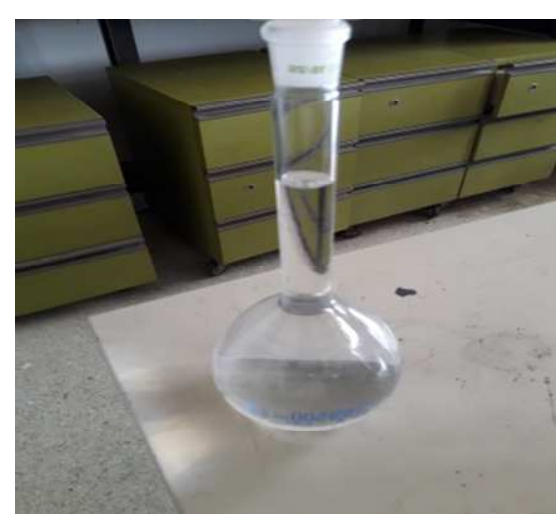

Figure 1. Aqueous Silver nitrate.

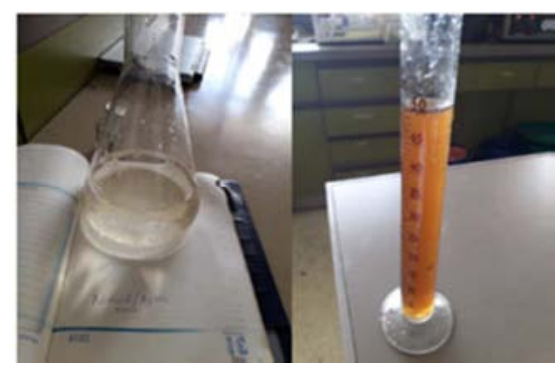

Figure 2. (Left) brown colour due to synthesized AgNPs, (right) dichloromethane-methanol plant extract. 


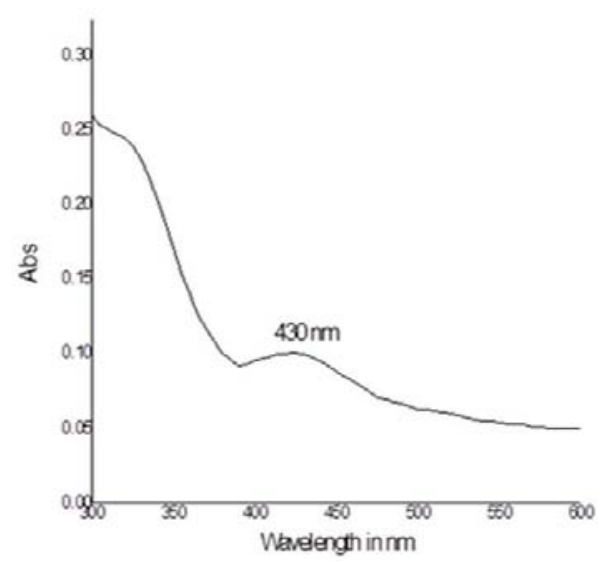

Figure 3. UV-vis spectrum of synthesized silver nanoparticles

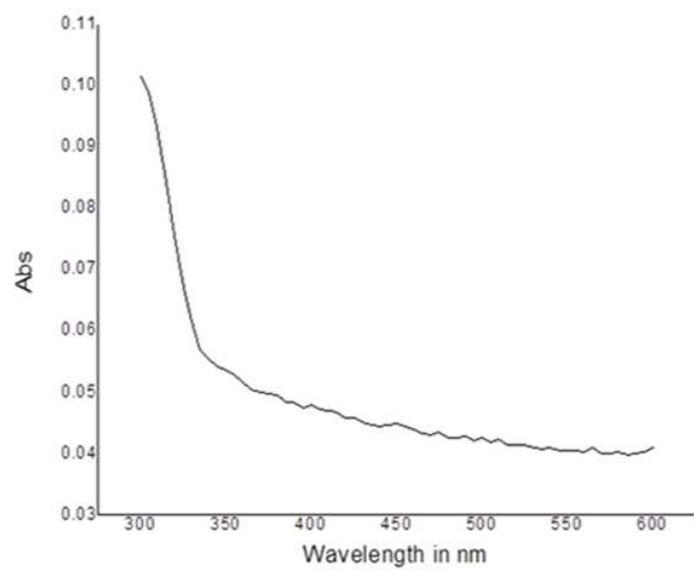

Figure 4. UV-vis spectrum of aqueous silver nitrate.

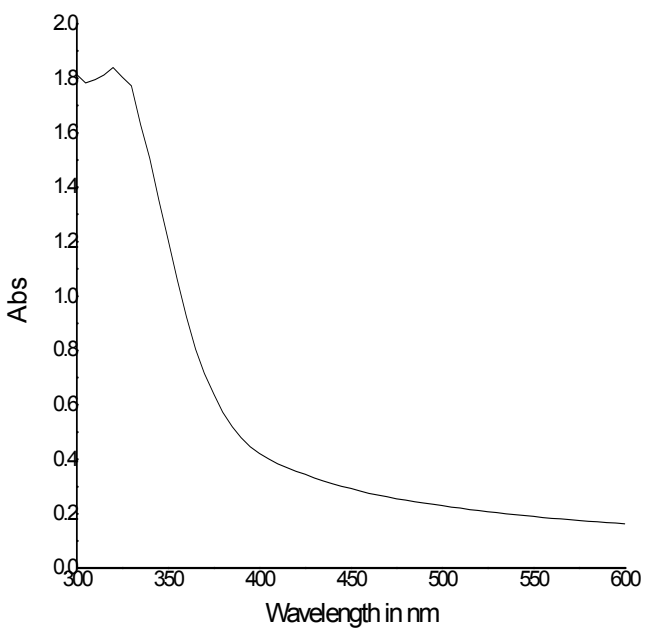

Figure 5. UV-vis spectrum of dichloromethane-methanol crude extract.

\subsection{SEM/EDX and TEM}

The surface morphology and elemental composition of synthesized silver nanoparticles were determined using SEM/EDX [24]. SEM image shown in figure 6, shows that the morphology of the nanoparticles were generally spherical and others aggregates of spherical shape. This observation has been observed in earlier studies [25].

The elemental constituents and relative abundance of the biosynthesize Ag NPs were determined using Energy Dispersive X-ray (EDX) as presented in figure 7. The spectrum showed strong signal at silver region which is around 3-3.7 kev. This is in agreement with other studies whereby metallic silver nanoparticles have been reported to show typical optical absorption peaks at approximately 3.7 $\mathrm{Kev}$ [26]. There were other peaks for $\mathrm{C}$ and $\mathrm{O}$ which acted as capping/stabilizing agents on the surface of the silver nanoparticles and they originated from plant extracts [24]. Presence of other peaks in EDX analysis belonging to other elements have been observed in other studies where plant extracts have been used to synthesize the metalic nanoparticles [26]. The percentage of Ag metal in occurrence with other chemical elements was significant with a percentage of $(81.33 \%)$ while other elements were oxygen $(3.23 \%)$, carbon $(15.44 \%)$. This is in line with a study done by (6) whereby carbon and oxygen were among the elements they observed and silver highest with a percentage of (70.36\%).

TEM micrograph in figure 8 revealed the size and general morphology of the nanoparticles [27]. The micrographs further confirmed the formation of spherical polydispersed nanoparticles, which is in agreement with the shape of the SPR band in the UV-visible spectrum [27]. The average size of the nanoparticles were $26.98 \mathrm{~nm}$ as shown in the histogram (Figure 9) as per the TEM micrographs in figure 8.

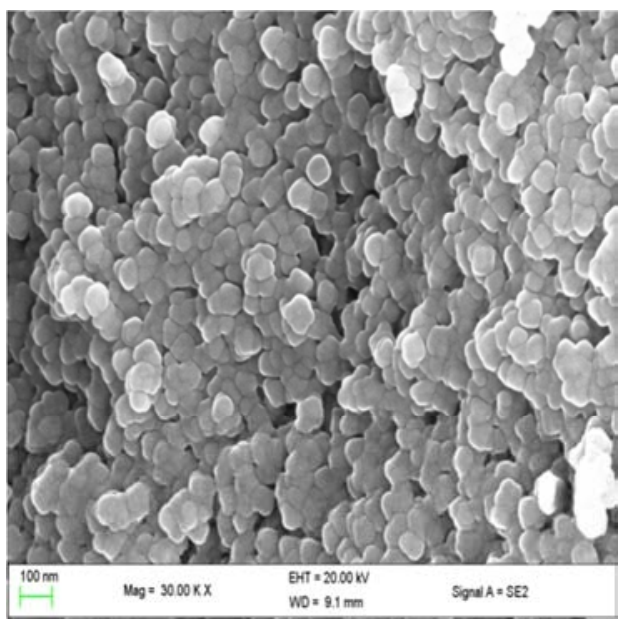

Figure 6. SEM micrograph of synthesized Ag NPs.

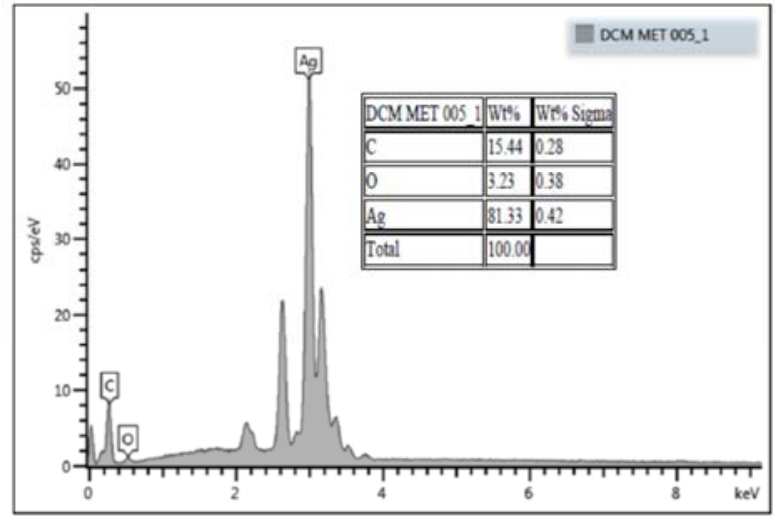

Figure 7. EDX spectra of synthesized Ag NPS. 


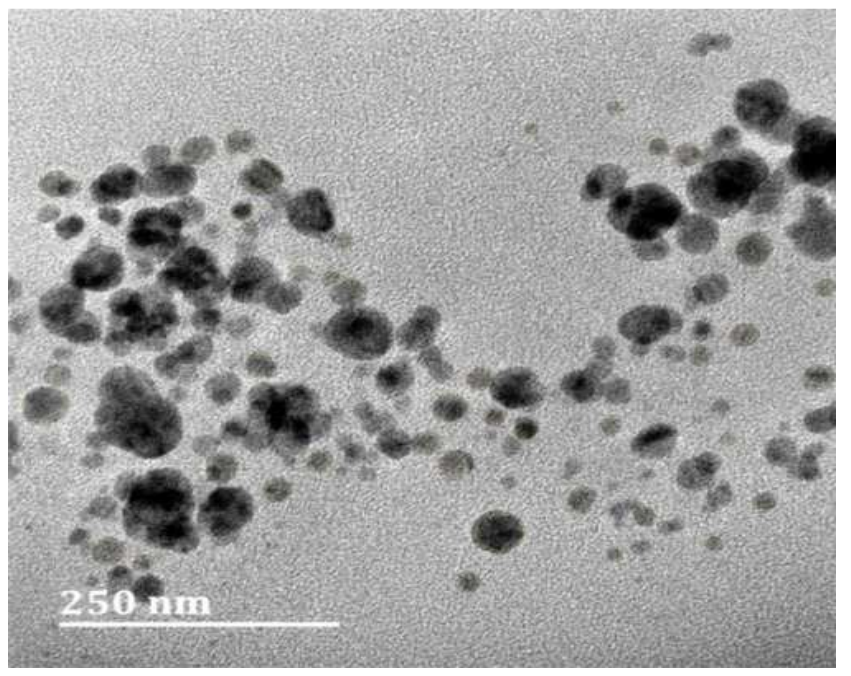

Figure 8. TEM micrograph of synthesized Ag NPS.

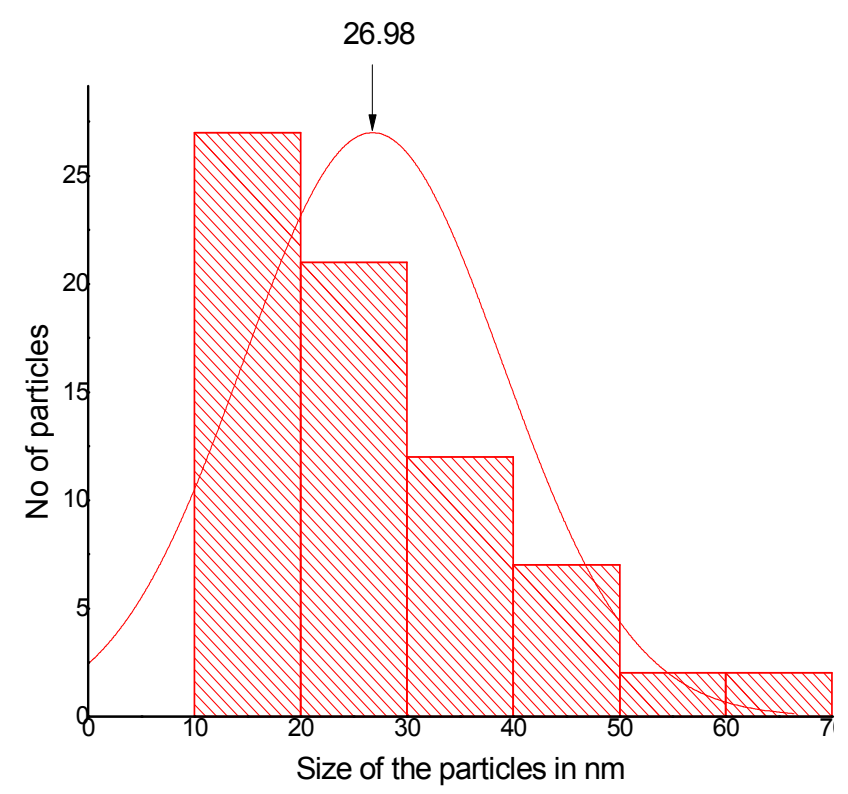

Figure 9. Particle size distribution of synthesized Ag NPs.

\subsection{FTIR Analysis}

The dual role of plant extracts as a reducing and stabilizing/ capping agent was observed when the FTIR spectra of the synthesized Ag NPs was analysed. The spectra showed bands with various absorption values. The absorption band at $3472.88 \mathrm{~cm}^{-1}$ and $3190.67 \mathrm{~cm}^{-1}$ corresponds to the strong stretching vibrations and weak stretching vibrations of hydroxyl group $(-\mathrm{OH})$ of phenolic compounds respectively [28]. The band at $1646.61 \mathrm{~cm}^{-1}$ corresponded to the $\mathrm{C}=\mathrm{C}$ in aromatic compounds of the phytochemicals [29]. The band at $1405.08 \mathrm{~cm}^{-1}$ indicate $\mathrm{S}=\mathrm{O}$ (sulfate ester) group [30]. The band at $1109.32 \mathrm{~cm}^{-1}$ confirmed the presence of carboxylic acid group [30]. The band at $518.64 \mathrm{~cm}^{-1}$ represent presence of alkyl halide $\mathrm{C}-\mathrm{Br}$. The phytochemical constituents of $C$. cineriaefolium extract interacted with silver nitrate through these functional groups and facilitate the reduction to silver nanoparticles [31].

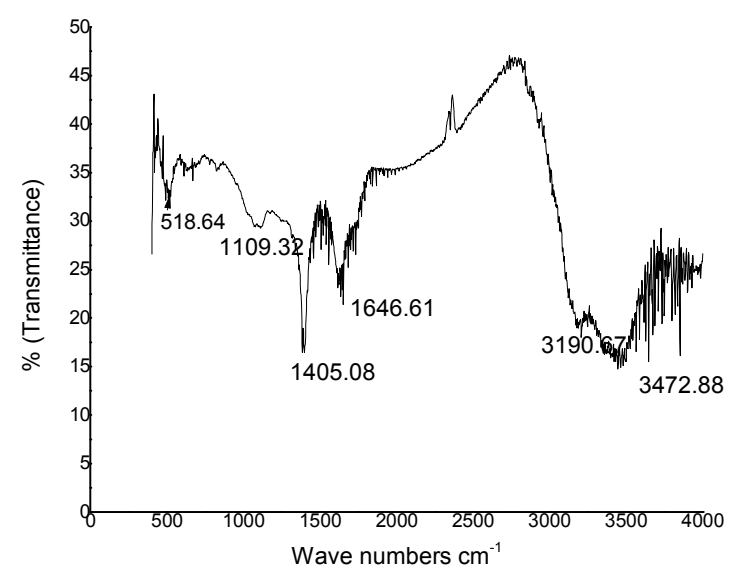

Figure 10. FTIR spectroscopy of Ag NPs.

\subsection{Phytochemical Analyses}

Results of the tested phytochemicals are tabulated in Table 1. Flavanoids, phenols, tannins and glycosides were present while saponins, alkaloids and terpenoids were absent.

Table 1. Phytochemical analysis of dichloromethane-methanol crude extract.

\begin{tabular}{ll}
\hline Phytochemicasl tested & Present (+)/ Absent (-) \\
\hline Saponins & - \\
Flavanoids & + \\
Alkaloids & - \\
Phenols & + \\
Tannins & + \\
Glycosides & + \\
Terpenoids & - \\
\hline
\end{tabular}

Phytochemicals have been reported to play crucial role in the synthesis of metalic nanoparticles since they act as reducing and capping/stabilizing agents in the synthesis of metal nanoparticles [8]. They also determine the shape of the nanoparticles [32]. The identified phytochemicals have been reported to reduce the silver ion to silver nanoparticles and stabilize the formed nanoparticles.

The major phytochemicals that have been implicated with synthesis of metal nanoparticles are flavonoids and phenolic compounds. This is due to presence of hydroxyl groups and carbonyl moieties [33]. For example quercetin, a flavonoid that has three potential bidentate binding sites, namely $\mathrm{h} \alpha$ hydroxy-carbonyl, $\beta$-hydroxy-carbonyl or catechol having two hydroxyl groups in ortho positions have been reported to form stable complex with metal cations such as Mo (VI), Fe (II)/Fe (III), Cu (II), Zn (II), Al (III), Tb (III), Pb (II), Co (II) [34]. Green synthesis of Ag NPs using both leaf extract of Ocimum sanctum and a flavonoid (quercetin) present in the extract was done separately [35].

Tannins present in oak bark extracts was reported to be responsible for the reduction of silver nanoparticles. Although tannin acid is identified as a weak reducer and forms germs of nanoparticles, the reduction of silver ions may be possible because of products of tannic acid hydrolysis - glucose, gallic acid [36]. Flavonoids, glycosides and carbohydrates in Lantana camara were reported to be responsible for the synthesis of silver nanoparticles [37]. 


\subsection{Antibacterial Activity of Silver Nanoparticles}

Overall in present study, the antibacterial activity of $\mathrm{Ag}$ NPs was higher than the antibacterial activity of silver ions in form of $\mathrm{AgNO}_{3}$ and plant extracts as shown in table 2, an indication that the silver nanoparticles exhibited good antimicrobial activity against selected pathogenic bacteria. This observation has been observed in previous studies [26].

Table 2. Antibacterial activity against selected organism.

\begin{tabular}{|c|c|c|c|c|}
\hline \multirow{2}{*}{ Extracts } & \multicolumn{4}{|c|}{ Micro-organisms } \\
\hline & $M R S A$ & S. aureus & P. aeruginosa & S. sonnie \\
\hline Ag NPs & $7.2 \pm 0.3$ & $10.8 \pm 0.8$ & $9.3 \pm 0.6$ & $9.5 \pm 0.5$ \\
\hline Control (plant extract) & $6 \pm 0$ & $6 \pm 0$ & $6 \pm 0$ & $6 \pm 0$ \\
\hline Control $\left(\mathrm{AgNO}_{3}\right)$ & $6.4 \pm 0.1$ & $7.2 \pm 0.3$ & $7 \pm 0.5$ & $7.1 \pm 0.3$ \\
\hline DMSO+distilled $\mathrm{H}_{2} \mathrm{O}^{\mathrm{Q}}$ & $6 \pm 0$ & $6 \pm 0$ & $6 \pm 0$ & $6 \pm 0$ \\
\hline Chlorampherical $^{\mathrm{P}}$ & $28.7 \pm 1$ & $22.7 \pm 1.2$ & $22 \pm 2$ & $30.5 \pm 1.3$ \\
\hline
\end{tabular}

${ }^{\mathrm{P}}$ Positive control, ${ }^{\mathrm{Q}}$ negative control

Silver inform of silver ions has been used widely medically due to its antibacterial properties [38]. The immense antibacterial properties that silver ions have is attributes to the high tendency of silver to bind to sulfur and phosphorus. These two components i.e sulfur and phosphorus are found abundantly throughout the membrane of bacterial cell. Silver ions therefore react with proteins containing sulfur inside or outside of the cell membrane hence affecting cell survival [39]. The Application of nanotechnology in the synthesis of silver nanoparticles have improved immensely the antimicrobial activity of Silver [40].

Based on the zone of inhibition, the nanoparticles were more active on $S$. aureus, a gram positive bacteria although there was no significant difference between the activity of the nanoparticles on $S$. aureus and the gram negative bacteria which were $P$. aeruginosa and $S$. sonnie. This similar observation has been reported [41]. The MIC of Ag NPs determined against S.aureus was $31.25 \mu \mathrm{g} / \mathrm{ml}$. This corroborate with previous study whereby the green synthesized Ag NPs using $A$. reticulata extract also had an MIC of $31.25 \mu \mathrm{g} / \mathrm{ml}$ against $S$. aureus [42].

Previous studies provide conflicting statements on the effect of nanoparticles on gram-positive and gram-negative bacteria. According to [43], gram-negative bacteria are more resistant to the effect of silver nanoparticles while [44, 45] showed that silver nanoparticles have equal inhibitory effect against both gram-positive and gram-negative strains. The ability of Ag NPs to act on both gram negative and gram positive bacteria has been ascertained in previous studies therefore the present study confirm the multifaceted strategy of Ag NPs [46].

The antibacterial properties of the nanoparticles are attributed to both the action of nanoparticles and the elution of silver ions [47]. The bactericidal activity of the nanoparticles is likely to be due to the attachment of the $\mathrm{Ag}$ NPs to the cell wall and the generation of free radicals. The free radicles disturb the permeability of the membrane by penetrating to the cell membrane and causing intracellular ATP leakage and cell death [46]. Furthermore, presence of
Ag NPs in the cell membrane of bacteria has been proven in earlier studies [48]. Another proposed mechanism is that silver ions are released during the interaction of Ag NPs with water or tissue fluid. The released silver ions penetrate the cell membrane and bind with the electron donor functional groups such as phosphates, thiols, and indoles which contain sulfur and phosphorous compounds [46]. Thus a combined effect between the activity of the nanoparticles and free ions contributes in different ways to produce a strong antibacterial activity of broad spectrum [49].

\section{Conclusion}

Silver nanoparticles were successfully synthesized through green synthesis using dichloromethane-methanol extract of $C$. cinerariaefolium commonly called pyrethrum. Green synthesis of silver nanoparticles have been considered cheap and environmentally friendly. The formation of the nanoparticles was first confirmed by a reddish brown color change due to SPR peak in the UV-Vis spectrum observed at $430 \mathrm{~nm}$. The resulting nanoparticles were characterized by SEM, EDX, TEM, and FTIR spectroscopy. The SEM micrographs revealed spherical shape morphology supported by the TEM result. Average size of the nanoparticles was $26.98 \mathrm{~nm}$ estimated from TEM images. EDX showed an intense signal of Ag with percentage abundance at $81.33 \%$. FTIR further confirmed the dual role of plant extracts as both reducing and stabilizing agents in the synthesis of nanoparticles. This study therefore confirmed that the synthesized silver nanoparticles are good antimicrobial agents and for this reason recommended as product of value in the field of nanobiotechnology and nanomedicine.

\section{References}

[1] Westh, H., Zinn, S., Rosdahl, V. T and Sarisa Study Group. (2004). An international multicenter study of antimicrobial consumption and resistance in Staphylococcus aureus isolates from 15 hospitals in 14 countries. Microbial Drug Resistance, 10 (2): 169-176.

[2] Bhalodia, N. R and Shukla, V. J. (2011). Antibacterial and antifungal activities from leaf extracts of Cassia fistula 1.: An ethnomedicinal plant. Journal of advanced pharmaceutical technology \& research, 2 (2): 104-109. https://doi.org/10.4103/2231-4040.82956.

[3] Franci, G., Falanga, A., Galdiero, S., Palomba, L., Rai, M., Morelli, G., and Galdiero, M. (2015). Review on Silver Nanoparticles as Potential Antibacterial Agents. Molecules. 20: 8856-8874; doi: 10.3390/molecules20058856.

[4] Nikam, A. P., Ratnaparkhiand, M. P., Chaudhari, S. P. (2014). Nanoparticles an overview. International Journal of Research and Development in Pharmacy and Life Sciences, 5: 1121-1127.

[5] Liem, L. N.,, The, N. P and Nguyen, D. (2019). Microwave Assisted Green Synthesis of Silver Nanoparticles Using Mulberry Leaves Extract and Silver Nitrate Solution. Technologies. 7, 7; 1-9. 
[6] Srirangam, G. M and Rao, K. P. (2017). Synthesis and charcterization of silver nanoparticles from the leaf extract of malachra capitata 10 (1): 46-53.

[7] Hazarika, D., Phukan, A., Saikia, E. and Chetia, B. (2014). Phytochemical screening and synthesis of silver nanoparticles using leaf extract of Rhynchotechum ellipticum. Int J Pharm Pharm Sci, 6 (1): 672-674.

[8] Swarnalatha, Y., Krishnan, D., Rajasekar, S. P. V.(2013). Antibacterial activity of biogenic silver nanoparticles from Sphaeranthus Amaranthoides. Int J Pharm Pharm Sci. 5 (4): 594-596.

[9] Doane, T. L., Burda, C. (2012). The unique role of nanoparticles in nanomedicine: imaging, drug delivery and therapy. Chem Soc Rev. 41: 2885-2911.

[10] Dreaden, E. C., El- Sayed, M. A. (2012). Detecting and destroying cancer cells in more than one way with noble metals and different confinement properties on the nanoscale. Acc Chem Res. 45: 1854-1865.

[11] Bedford, E. E., Spadavecchia, J., Pradier, C. M., Gu, F. X.(2012). Surface plasmon resonance biosensors incorporating gold nanoparticles. Macromol Biosci. 12: 724739.

[12] An, K., Somerjai GA. (2012). Size and shape control of metal nanoparticles for reaction selectivity in catalysis. Chem Cat Chem. 4: 1512-1524.

[13] Baruah, B, Craighead C, Abolarin C. (2012). One phase synthesis of surface modified gold nanoparticles and generation of SERS substrate by seed growth method. Langmuir. 28: 15168- 15176.

[14] Rai, M., Yadav, A., Gade A. (2009). Silver nanoparticles as a new generation of antimicrobials, Biotechnol. Adv. 27: 76-83.

[15] Iravani, S. (2011). Green synthesis of metal nanoparticles using plants, Green Chem. 13: 2638-2650.

[16] De Soyza, S. G., Wijayaratne, W. M. D. G. B., Napagoda, M., Witharana, S. (2017) Antimicrobial Potential in Biogenic Silver nanoparticles Synthesized from Plectranthus zeylanicus. J Mol Nanot Nanom 1 (1): 105.

[17] Khan A. M., Qureshi R. A., Ullah F., Gilani S. A., Nosheen A., Sahreen S., Laghari M. K., Laghari M. Y., Rehman S. U., Hussain I. and Murad W. (2011). Phytochemical analysis of selected medicinal plants of Margalla Hills and surroundings, Journal of Medicinal Plants Research, 5 (25): 6017- 6023.

[18] Clinical and Laboratory Standards Institute. (2009). Methods for dilution antimicrobial susceptibility tests for bacteria that grow aerobically; approved standard - eighth edition. Wayne: Clinical and Laboratory Standards Institute.

[19] NCCLS (2000). Performance standards for antimicrobial disk susceptibility tests. Approved standard, $7^{\text {th }}$ ed. NCCLS document M2-A7. NCCLS, Wayne, Pa.

[20] Chandran, S. P., Chaudhary, M., Pasricha, R., Ahmad, A., Sastry, M. (2006). Synthesis of gold nanotriangles and silver nanoparticles using Aloe vera plant extract. Biotechnol. Prog. 22: $577-583$.

[21] Priya, M. M., Selvi, B. K., Paul, J. A. (2011). Green synthesis of silver nanoparticles from the leaf extracts of Euphorbia hirta and Nerium indicum. Digest Journal of Nanomaterials \&
Biostructures (DJNB), 6 (2): 869-877.

[22] Megiel, E.,(2017). Surface modification using TEMPO and its derivatives. Adv. Colloid Interface Sci. 250: 158-184.

[23] Ponarulselvam, S., Panneerselvam, C., Murugan, K., Aarthi, N., Kalimuthu, K., Thangamani, S. (2012). Synthesis of silver nanoparticles using leaves of Catharanthus roseus Linn. G. Don and their antiplasmodial activities, Asian Pac J Trop Biomed 2 (7): 574-580.

[24] Dada, A. O., Adekola, F. A., Odebunmi, E. O., 2017d. A novel zerovalent manganesefor removal of copper ions: synthesis, characterization and adsorption studies. Appl. Water Sci. 7 (3): $1409-1427$

[25] Abiola Grace Femi-Adepoju, Adewumi Oluwasogo Dada, Kabir Opeyemi Otun, Adeyinka Olufemi Adepoju, Ojo Paul Fatoba. (2019). Green synthesis of silver nanoparticles using terrestrial fern (Gleichenia Pectinata (Willd.) C. Presl.): characterization and antimicrobial studies. Heliyon. 1-18.

[26] Khan F, A., Zahoor, M., Jalal A., and Rahman, A. U. (2016). Green Synthesis of Silver Nanoparticles byUsing Ziziphus nummularia LeavesAqueous Extract andTheir Biological Activities. Hindawi Publishing Corporation Journal of Nanomaterials.

[27] Almalah, H., Alzahrani H, A., Abdelkader H, S. (2019). Green Synthesis of Silver Nanoparticles using Cinnamomum Zylinicum and their Synergistic Effect against Multi-Drug Resistance Bacteria.

[28] Vanaja, M., Gnanajobitha, G., Paulkumar, K., Rajeshkumar, S., Malarkodi, C., Annadurai, G.: Phytosynthesis of silver nanoparticles by Cissus quadrangularis: influence of physicochemical factors. J. Nanostruct. Chem. 3, 1-8 (2013).

[29] Raghunandan, D., Bedre, M. D., Basavaraja, S., Sawle, B., Manjunath, S., Venkataraman, A. (2010). Rapid biosynthesis of irregular shaped gold nanoparticles from macerated aqueous extracellular dried clove buds (Syzygium aromaticum) solution. Colloids Surf. B, 79: 235-240.

[30] Pirtarighat, S., Ghannadnia, M., Baghshahi, S. (2019). Green synthesis of silver nanoparticles using the plant extract of Salvia spinosa grown in vitro and their antibacterial activity assessment. Journal of Nanostructure in Chemistry, 9: 1-9.

[31] Bar, H., Bhui, D. K., Sahoo, G. P., Sarkar, P., Pyne, S., \& Misra, A. (2009). Green synthesis of silver nanoparticles using seed extract of Jatropha curcas. Colloids and Surfaces A: Physicochemical and Engineering Aspects, 348 (1-3): 212216.

[32] Padalia, H., Moteriya, P., \& Chanda, S. (2015). Green synthesis of silver nanoparticles from marigold flower and its synergistic antimicrobial potential. Arabian Journal of Chemistry, 8(5), 732-741.

[33] Marslin, G., Siram, K., Maqbool, Q., Selvakesavan, R. K., Kruszka, D., Kachlicki, P., \& Franklin, G. (2018). Secondary metabolites in the green synthesis of metallic nanoparticles. Materials, 11 (6): 940.

[34] Cherrak, S. A., Mokhtari-Soulimane, N., Berroukeche, F., Bensenane, B., Cherbonnel, A., Merzouk, H., and Elhabiri, M. (2016). In vitro antioxidant versus metal ion chelating properties of flavonoids: A structure-activity investigation. PloS one, 11 (10): $\mathrm{e} 0165575$. 
[35] Jain, S., Mehata, M. S. (2017). Medicinal plant leaf extract and pure flavonoid mediated green synthesis of silver nanoparticles and their enhanced antibacterial property. Scientific reports, 7 (1): 1-13.

[36] Puišo J., Jakevičius, L., Mačionienè I. (2012). Ultrasound assiste synthesis of silver nanoparticles in juniper extract. Medical Physics in the Baltic States, Kaunas. PP 46-50.

[37] Ajitha, B., Ashok Kumar Reddy, Y., Shameer, S., Rajesh, K. M., Suneetha, Y., Sreedhara Reddy, P. (2015). Lantana camara leaf extract mediated silver nanoparticles: Antibacterial, green catalyst. J. Photochem. Photobiol. B, 149: 84-92.

[38] Lok, C. N., Ho, C. M., Chen, R., He, Q. Y., Yu, W. Y., Sun, H. Tam, P. K. H., Chiu, J. F., Che, C. M. (2006). Proteomic analysis of the mode of antibacterial action of silver nanoparticles. J. Proteome Res. 5: 916-924.

[39] Tamboli, D. P., Lee, D. S. (2013). Mechanistic antimicrobial approach of extracellularly synthesized silver nanoparticles against gram positive and gram negative bacteria, J Hazard Mater. 260: 878-884.

[40] Huh, A. J.; Kwon, Y. J. "Nanoantibiotics": a new paradigm for treating infectious diseases using nanomaterials in the antibiotics resistant era. Journal of controlled release, 156: $128-145$.

[41] Sasikala, A., Linga Rao, M., Savithramma, N., Prasad, T. N. V. K. V (2015). "Synthesis of silver nanoparticles from stem bark of Cochlospermum religiosum (L.) Alston: an important medicinal plant and evaluation of their antimicrobial efficacy" Appl. Nanosci., 5: 827-835.

[42] Parthiban, E., Manivannan, N., Ramanibai, R., \& Mathivanan, N. (2019). Green synthesis of silver-nanoparticles from
Annona reticulata leaves aqueous extract and its mosquito larvicidal and anti-microbial activity on human pathogens. Biotechnology Reports, 21, e00297.

[43] Shrivastava S., Bera T., Roy A., Singh G., Ramachandrarao P., Dash D. (2007). Characterization of enhanced antibacterial effects of novel silver nanoparticles. Nanotechnology. 18: 225-103.

[44] Kong H and Jang J. (2008). Antibacterial properties of novel poly (methyl methacrylate) nanofiber containing silver nanoparticles. Langmuir, 24: 2051-2056.

[45] Peticae A., Gavriliu S., Lungua M., Burunteaa N., Panzarub C. (2008). Colloidal silver solutions with antimicrobial properties. Materials Science and Engineering: 152: 22-27.

[46] Franci, G., Falanga, A., Galdiero, S., Palomba, L., Rai, M., Morelli, G., and Galdiero M. (2015). Review on Silver Nanoparticles as Potential Antibacterial Agents. Molecules. 20: 8856-8874; doi: 10.3390/molecules20058856.

[47] Choi, O., Hu, Z. (2008). Size dependent and reactive oxygen species related nanosilver toxicity to nitrifying bacteria. Environ. Sci. Technol. 42: 4583-4588.

[48] Oves, M., Aslam, M., Rauf, M. A., Qayyum, S., Qari, H. A., Khan, M. S., Alam, M. Z., Tabrez, S., Pugazhendhi, A., Ismail, I. M. (2018). Antimicrobial and anticancer activities of silver nanoparticles synthesized from the root hair extract of Phoenix dactylifera. Mater. Sci. Eng. C. 89: 429-443.

[49] Silver, S. (2003). Bacterial silver resistance: Molecular biology and uses and misuses of silver compounds. FEMS Microbiol. Rev. 27: 341-353. 